\title{
Evaluation of 2 portable ion-selective electrode meters for determining whole blood, plasma, urine, milk, and abomasal fluid potassium concentrations in dairy cattle
}

\author{
A. A. Megahed, ${ }^{*}$ M. W. H. Hiew, ${ }^{*}$ W. Grünberg, ${ }^{* 1}$ and P. D. Constable $\dagger^{2}$ \\ *Department of Veterinary Clinical Sciences, College of Veterinary Medicine, Purdue University, West Lafayette, IN 47907 \\ †Department of Veterinary Clinical Medicine, College of Veterinary Medicine, University of Illinois at Urbana-Champaign 61802
}

\begin{abstract}
Two low-cost ion-selective electrode (ISE) handheld meters (CARDY C-131, LAQUAtwin B-731; Horiba Ltd., Albany, NY) have recently become available for measuring the potassium concentration $\left(\left[\mathrm{K}^{+}\right]\right)$in biological fluids. The primary objective of this study was to characterize the analytical performance of the ISE meters in measuring $\left[\mathrm{K}^{+}\right]$in bovine whole blood, plasma, urine, milk, and abomasal fluid. We completed 6 method comparison studies using 369 whole blood and plasma samples from 106 healthy periparturient Holstein-Friesian cows, 138 plasma samples from 27 periparturient Holstein-Friesian cows, 92 milk samples and 204 urine samples from 16 lactating HolsteinFriesian cows, and 94 abomasal fluid samples from 6 male Holstein-Friesian calves. Deming regression and Bland-Altman plots were used to characterize meter performance against reference methods (indirect ISE, Hitachi 911 and 917; inductively coupled plasma-optical emission spectroscopy). The CARDY ISE meter applied directly in plasma measured $\left[\mathrm{K}^{+}\right]$as being $7.3 \%$ lower than the indirect ISE reference method, consistent with the recommended adjustment of $+7.5 \%$ when indirect ISE methods are used to analyze plasma. The LAQUAtwin ISE meter run in direct mode measured fat-free milk $\left[\mathrm{K}^{+}\right]$as being $3.6 \%$ lower than the indirect ISE reference method, consistent with a herd milk protein percentage of $3.4 \%$. The LAQUAtwin ISE meter accurately measured abomasal fluid $\left[\mathrm{K}^{+}\right]$compared to the indirect ISE reference method. The LAQUAtwin ISE meter accurately measured urine $\left[\mathrm{K}^{+}\right]$compared to the indirect ISE reference method, but the median measured value for urine $\left[\mathrm{K}^{+}\right]$was $83 \%$ of the true value measured by inductively coupled plasma-optical emis-
\end{abstract}

Received December 26, 2015.

Accepted April 5, 2016.

${ }^{1}$ Current address: University of Veterinary Medicine Hannover, Clinic for Cattle, Bischofsholer Damm 15, 30173 Hanover, Germany.

${ }^{2}$ Corresponding author: constabl@illinois.edu sion spectroscopy. We conclude that the CARDY and LAQUAtwin ISE meters are practical, low-cost, rapid, accurate point-of-care instruments suitable for measuring $\left[\mathrm{K}^{+}\right]$in whole blood, plasma, milk, and abomasal fluid samples from cattle. Ion-selective electrode methodology is not suitable for measuring $\left[\mathrm{K}^{+}\right]$in bovine urine.

Key words: hypokalemia, point-of-care

\section{INTRODUCTION}

Hypokalemia is common in lactating dairy cattle with abomasal displacement or volvulus, developing in response to alkalemia secondary to sequestration of chloride in the gastrointestinal tract (Constable et al., 1991; Rohn et al., 2004). Low feed intake, obligatory loss of potassium in milk ( $1.4 \mathrm{~g}$ of $\mathrm{K} / \mathrm{L}$ of milk), hyperglycemia, and hypovolemia are also considered main predisposing factors (Constable et al., 2013). Hypokalemia is also common in lactating dairy cattle with abomasal impaction (Wittek et al., 2005), clinical mastitis (Ohtsuka et al., 1997; Smith et al., 2001), and retained placenta (Hashem and Amer, 2008). Lactating dairy cattle with hepatic lipidosis and cattle receiving multiple injections of isoflupredone acetate as part of the treatment of ketosis are more susceptible to hypokalemia (Neff et al., 1960; Kalaitzakis et al., 2010; Sattler and Fecteau, 2014). The development of optimal treatment protocols for hypokalemic dairy cattle requires accurate, rapid, and repeated measurements of whole blood, plasma, or serum potassium concentration $\left(\left[\mathrm{K}^{+}\right]\right)$because the clinical signs of hypokalemia are nonspecific (Radostits et al., 2007; Sattler and Fecteau, 2014) and excessive potassium administration can be fatal (Constable, et al., 2014).

Hypokalemia is most commonly defined in adult cattle as serum $\left[\mathrm{K}^{+}\right]<3.9 \mathrm{mEq} / \mathrm{L}$ (Radostits et al., 2007; Constable et al., 2013). Plasma $\left[\mathrm{K}^{+}\right]$is approximately $0.4 \mathrm{mEq} / \mathrm{L}$ lower than serum $\left[\mathrm{K}^{+}\right]$because intracellular potassium is released from platelets during clotting (Hartland and Neary, 1999); consequently, plasma is 
preferred to serum for the accurate measurement of blood $\left[\mathrm{K}^{+}\right]$. Plasma $\left[\mathrm{K}^{+}\right]$is widely accepted to accurately reflect intracellular potassium stores in euglycemic or hypoglycemic animals with a blood $\mathrm{pH}$ within the reference range; however, it is generally believed that in severe alkalemia, plasma $\left[\mathrm{K}^{+}\right]$must be $<2.5 \mathrm{mEq} / \mathrm{L}$ for clinically significant intracellular potassium depletion to be present (Burnell and Scribner, 1957).

A variety of analytical procedures have been developed to measure the total or ionized $\left[\mathrm{K}^{+}\right]$in blood and other biological fluids, and these procedures have distinct advantages and disadvantages (Fogh-Andersen et al., 1984; Maas et al., 1985; Burnett et al., 2000; D'Orazio et al., 2000; Buzanovskii, 2015). Ion-selective potentiometry has become the dominant methodology for the analysis of ionized $\left[\mathrm{K}^{+}\right]$in many biological fluids because it is accurate, rapid, and inexpensive (Burnett et al., 2000; D'Orazio et al., 2000). Ion-selective electrode (ISE) methods have 3 main components: (1) a polyvinyl chloride membrane containing the antibiotic valinomycin that provides a selectively permeable barrier to potassium ions; (2) an internal filling solution with a weak fixed concentration of potassium ions that is separated from the test solution by the selectively permeable membrane; and (3) an internal reference electrode with a known potassium ion activity (Kimura et al., 1979; Anker et al., 1983). Following application of the test solution to the sensor, potassium ions rapidly diffuse through the selectively permeable membrane, and at equilibrium, the difference in potassium ion activity between the test solution and internal filling solution generates an electrical potential that is compared with the reference electrode. The potassium ion activity in the test solution is then calculated using the Nernst equation (Oesch et al., 1986).

The clinical application of ISE technology uses 2 approaches: direct ISE, which uses an undiluted sample, and indirect ISE, which uses a diluted sample. Direct ISE technologies, which measure the electrolyte activity in the water phase of a fluid, are widely used in pointof-care devices. Consequently, when direct ISE methods are applied to whole blood or milk, the measured electrolyte activity is not affected by the plasma protein concentration and packed cell volume or the fat and protein percentage, respectively. In contrast, indirect ISE technologies are extensively used in clinical pathology laboratories because they require a low volume of sample and provide a larger analytical range, which permits measuring electrolyte activity in fluids other than plasma or serum, such as urine, milk, saliva, and sweat (Dimeski et al., 2012). However, the extensive sample dilution in indirect potentiometry means that changes in the volume of the nonaqueous portion of the sample (such as a change in the protein concentration in whole blood, plasma, and serum from the assumed reference value of $70 \mathrm{~g} / \mathrm{L}$ or the presence of hyperlipidemia) results in underestimated plasma or serum $\left[\mathrm{K}^{+}\right]$ in hyperproteinemic and hyperlipidemic samples and overestimated potassium concentrations in hypoproteinemic samples (D'Orazio et al., 2000; Dimeski and Barnett, 2005; Dimeski et al., 2006; Jain et al., 2009). As a consequence, whole blood, plasma, and serum $\left[\mathrm{K}^{+}\right]$ values measured by indirect ISE should be increased by $7.5 \%(1 /[1-0.070])$ (D'Orazio et al., 2000). A second analytical issue is the application of ion-selective potentiometry to urine, which is a complex matrix with variable $\mathrm{pH}$, ionic strength, and cation-anion concentration. Initial studies of ISE methodology in undiluted human urine indicated the presence of anion interference (Jenny et al., 1980; Oesch et al., 1986), which was satisfactorily addressed by diluting the urine sample before analysis (Ladenson, 1979; Jenny et al., 1980). A subsequent study indicated that dilution of urine from cattle, sheep, horses, and cats failed to remove the anionic interference, resulting in underestimation of urinary $\left[\mathrm{K}^{+}\right]$in these species (Brooks et al., 1988). The interference was attributed to the presence of a low molecular weight anionic or zwitterionic compound in urine that electrostatically bound potassium, thereby making potassium ions unavailable for measurement by ISE methodology (Brooks et al., 1988).

Two handheld meters (CARDY C-131 and LAQUAtwin B-731; Horiba Ltd., Albany, NY) have recently become available for the measurement of $\left[\mathrm{K}^{+}\right]$in biological fluids. The meters use the same direct ISE technology, but they differ in external design in that the LAQUAtwin meter can be dipped directly into the solution. The meters are not currently approved for medical use by the US Food and Drug Administration. The low cost ( $\$ 260$ for the CARDY; $\$ 350$ for the LAQUAtwin) and portability of the meters make them potentially useful for on-farm measurement of $\left[\mathrm{K}^{+}\right]$in whole blood, milk, and other fluids from dairy cattle. We therefore hypothesized that the Horiba handheld ISE meters would provide an accurate and practical method for measuring $\left[\mathrm{K}^{+}\right]$in whole blood, plasma, milk, and abomasal fluid but not urine from cattle. The objective of this study was therefore to determine the analytical performance of the Horiba portable ISE meters in measuring $\left[\mathrm{K}^{+}\right]$in bovine whole blood, plasma, urine, milk, and abomasal fluid samples.

\section{MATERIALS AND METHODS}

All methods were evaluated and approved by the Purdue Animal Care and Use Committee. 


\section{Measurement of Whole Blood and Plasma $\left[\mathrm{K}^{+}\right]$}

Whole blood samples were collected into lithium heparin tubes from 106 healthy periparturient HolsteinFriesian cattle as described elsewhere (Megahed et al., 2015). The samples were rapidly transported to an adjacent climate-controlled laboratory area and whole blood $\left[\mathrm{K}^{+}\right]$was measured within 15 min of sample collection using an ISE meter (CARDY C-131 $\mathrm{K}^{+}$meter) according to the manufacturer's recommendations. The displayed value in parts per million (equivalent to $\mathrm{mg} / \mathrm{L}$ ) was multiplied by 0.026 (the reciprocal of the molecular weight of potassium $=39.1 \mathrm{~g} / \mathrm{mol}=39.1$ $\mathrm{mg} / \mathrm{mmol}$ ) to obtain the preferred units of millimoles per liter equal to milliequivalents per liter. The meter has a total display range of $(0-99) \times 100 \mathrm{ppm}$ in 3 automatically switched ranges: the $\times 1$ range (resolution, $1 \mathrm{ppm}=0.026 \mathrm{mEq} / \mathrm{L})$, the $\times 10$ range $(100-990$ $\mathrm{ppm}=2.6-25.7 \mathrm{mEq} / \mathrm{L}$; resolution, $10 \mathrm{ppm}=0.26$ $\mathrm{mEq} / \mathrm{L})$, and the $\times 100$ range $(1,000-9,900 \mathrm{ppm}=$ 26-257 mEq/L; resolution, $100 \mathrm{ppm}=2.6 \mathrm{mEq} / \mathrm{L}$ ). The manufacturer reported repeatability as $\pm 10 \%$ over a pH range of 2 to 9 . Selectivity coefficients (concentration ratio of the interfering ion against the target ion) to other monovalent or divalent cations were reported as follows: $\mathrm{Rb}^{+}=1 \times 10^{-1} ; \mathrm{NH}_{4}^{+}=7 \times 10^{-3} ; \mathrm{Cs}^{+}=$ $4 \times 10^{-3} ; \mathrm{Na}^{+}=3 \times 10^{-4} ; \mathrm{Mg}^{2+}=1 \times 10^{-5} ; \mathrm{Ca}^{2+}=$ $7 \times 10^{-7}$. The meter corrects the ISE measurement for temperature, and the operating temperature range was reported to be $5^{\circ} \mathrm{C}$ to $40^{\circ} \mathrm{C}$ at up to $85 \%$ relative humidity.

The manufacturer recommends that a 1-point calibration be performed each day. We elected to calibrate the meter daily using a 2-point calibration method and standard potassium solutions $(150 \mathrm{ppm}=3.9 \mathrm{mEq} / \mathrm{L}$; $2,000 \mathrm{ppm}=52 \mathrm{mEq} / \mathrm{L}$ ) provided by the manufacturer because we were measuring fluid samples with a wide range of $\left[\mathrm{K}^{+}\right]$. Two to three drops of heparinized whole blood were placed on the flat sensor pad to ensure that the 2 visible sensors were covered. The presence of sufficient blood or other fluid on the flat sensor pad generates a potential difference between the sample solution and the internal filling solution that is directly related to the amount of $\mathrm{K}^{+}$in the sample, based on the Nernst equation (Oesch et al., 1986). The reading on the liquid crystal display screen became stable within $45 \mathrm{~s}$, and the value was recorded after that time. The response time of the meter depends on different factors in the sample such as $\left[\mathrm{K}^{+}\right]$, ionic strength, protein content, and lipid content (Lang et al., 2002). The sensor pad was then rinsed with deionized water and gently wiped until the display read 0. A 2-point calibration was repeated after every 20 samples to maintain instrument accuracy, as recommended by the manufacturer. The same methodologic steps were applied with the LAQUAtwin B-731 $\mathrm{K}^{+}$meter.

The remainder of the heparinized whole blood sample was then centrifuged for 5 min at 1,400 $\times g$. Plasma was harvested, and plasma $\left[\mathrm{K}^{+}\right]$was immediately measured as already described for heparinized whole blood using the same ISE meter. The time interval between measuring whole blood and plasma $\left[\mathrm{K}^{+}\right]$was always $<30 \mathrm{~min}$. After that, plasma was transferred into polypropylene vials within $1 \mathrm{~h}$ of centrifugation and stored at $-20^{\circ} \mathrm{C}$ for later measurement by the reference method.

Stored plasma samples were also analyzed; these samples were collected from a second group of cattle comprising 15 healthy periparturient Holstein-Friesian cows as described elsewhere (Grünberg et al., 2011). The plasma samples had been stored at $-80^{\circ} \mathrm{C}$ for up to $3 \mathrm{yr}$ and were thawed at room temperature, and the $\left[\mathrm{K}^{+}\right]$was measured directly using an ISE meter (CARDY C-131 $\mathrm{K}^{+}$meter). Stored plasma samples that had a larger proportion of low plasma $\left[\mathrm{K}^{+}\right]$were also analyzed; these samples were collected from a third group of cattle comprising 12 lactating HolsteinFriesian cows with experimentally induced free water, electrolyte, and acid-base imbalances as described elsewhere (Constable et al., 2014). The plasma samples had been stored at $-20^{\circ} \mathrm{C}$ for up to $2 \mathrm{yr}$, were thawed at room temperature, and were measured as described previously using the same ISE meter (CARDY C-131 $\mathrm{K}^{+}$meter).

\section{Measurement of Urine $\left[\mathrm{K}^{+}\right]$}

Urine samples were collected from 16 lactating Holstein-Friesian cows with experimentally induced free water, electrolyte, and acid-base imbalances as described elsewhere (Constable et al., 2014). The urine samples had been stored at $-20^{\circ} \mathrm{C}$ for up to $2 \mathrm{yr}$ and were thawed at room temperature, vortexed, and diluted 1:19 with distilled water to minimize the ion-binding effects of low molecular weight zwitterions present in bovine urine (Brooks et al., 1988). The $\left[\mathrm{K}^{+}\right]$of diluted urine was measured using an ISE meter (LAQUAtwin $\mathrm{K}^{+}$meter) in the same manner as described for whole blood and plasma, and the measured value was corrected for dilution.

\section{Measurement of Milk $\left[K^{+}\right]$}

Milk samples were collected from 16 lactating Holstein-Friesian cows with experimentally induced free water, electrolyte, and acid-base imbalances as described elsewhere (Constable et al., 2014). The milk samples had been stored at $-20^{\circ} \mathrm{C}$ for up to $2 \mathrm{yr}$ and were thawed at room temperature. The $\left[\mathrm{K}^{+}\right]$was 
measured using an ISE meter (LAQUAtwin $\mathrm{K}^{+}$meter) in the same manner as described previously for whole blood and plasma, avoiding any fat aggregation in the drops placed on sensor pad.

\section{Measurement of Abomasal Fluid $\left[\mathrm{K}^{+}\right]$}

Abomasal fluid samples were collected from 6 healthy male Holstein-Friesian calves via a surgically placed abomasal cannulas as described elsewhere (Constable et al., 2009). Calves were fed fresh cow milk (approximately $3.5 \%$ fat, $3.4 \%$ protein) with or without the addition of 1 of 2 commercially available oral rehydration solutions that contained potassium. The samples had been stored at $-20^{\circ} \mathrm{C}$ for up to $5 \mathrm{yr}$ and were thawed at room temperature, and the $\left[\mathrm{K}^{+}\right]$was measured directly using an ISE meter (LAQUAtwin $\mathrm{K}^{+}$meter) in the same manner as described for plasma.

\section{Reference Methods for Measuring Plasma, Urine, Milk, and Abomasal Fluid $\left[K^{+}\right]$}

Plasma, urine, milk, and abomasal fluid samples were analyzed at the Veterinary Diagnostic Laboratory at the University of Illinois Urbana-Champaign using ion-selective potentiometry via an automated analyzer (plasma, urine, milk: Hitachi 911, Roche Diagnostics, Basel, Switzerland; abomasal fluid, Hitachi 917, Roche Diagnostics). These automated analyzers use a liquid-liquid junction type of ISE and dilute the sample 1:31 with boric acid $(650 \mathrm{mmol} / \mathrm{L})$ to acidify it before analysis; consequently, this reference method was indirect in comparison to a direct test method in which the sample is not diluted for analysis. Some of the plasma samples were obtained from cattle with experimentally induced dehydration, and they consequently had a higher plasma protein concentration than the assumed constant plasma protein concentration of $70 \mathrm{~g} / \mathrm{L}$. The ISE meter, which employs direct potentiometry, was anticipated to measure lower $\left[\mathrm{K}^{+}\right]$values than the reference method for plasma and milk because the reference method employed indirect potentiometry with a standard correction factor. Milk samples were centrifuged and the fat layer removed before the samples were analyzed by the reference method. Potentiometry is a suitable method to measure milk $\left[\mathrm{K}^{+}\right]$(Hitti and Thomas, 1985) because potassium in milk is $>95 \%$ dissociated, with $<5 \%$ being bound to casein and other milk proteins in the micellar phase (Holt et al., 1981). Moreover, potentiometric determination of milk $\left[\mathrm{K}^{+}\right]$is minimally affected by pH (Le Graët and Brulé, 1993; Mekmene et al., 2010).

Urine $\left[\mathrm{K}^{+}\right]$was also measured using a second reference method employing inductively coupled plasma-optical emission spectroscopy (ICP-OES; Optima 4300 DV, Perkin Elmer Instruments LLC, Norwalk, CT). The ICP-OES methodology is considered the gold-standard method for analyzing potassium content in complex matrices such as urine (Krejčová et al., 2001).

\section{Statistical Analysis}

Data are expressed as mean $\pm \mathrm{SD}$ or as median and range based on the Shapiro-Wilk test for normality, and $P<0.05$ indicated statistical significance. Withinday repeatability was evaluated by calculating the coefficient of variation (CV) from 20 consecutive analyses of a purposively collected sample on the same day. Between-day repeatability was evaluated by calculating the CV for selected aqueous standard solutions.

Deming regression was used to evaluate the relationship between whole blood and plasma $\left[\mathrm{K}^{+}\right]$measured by the ISE meter and plasma, urine, milk, and abomasal fluid $\left[\mathrm{K}^{+}\right]$measured by the ISE meter and reference methods (Martin, 2000). The CV value was used for the middle of the range for each analytical method. For Deming regression, the intercept value reflects constant bias and the slope reflects proportional bias. Agreement was also examined through Bland-Altman difference plots, using the percentage difference relative to the mean of the 2 measurements. The upper and lower limits of agreement were calculated from the bias $\pm 1.96 \times \mathrm{SD}$. The bias estimate from BlandAltman plots reflected the mean bias over the range of measured values and therefore included both the constant and proportional bias identified using Deming regression. Based on the imperfect measurement accuracy of the reference methodology, resolution of the meter, and reported repeatability of the meter of $\pm 10 \%$, we assigned $\pm 15 \%$ as a priori acceptable limits of agreement. Statistical analyses were performed using MedCalc Statistical Software version 15.11.4 (MedCalc Software bvba, Ostend, Belgium, 2015) and SAS 9.3 (SAS Institute Inc., Cary, NC).

\section{RESULTS}

\section{Repeatability}

The mean within-day CV for whole blood samples with $\left[\mathrm{K}^{+}\right]$values of $2.9,4.1$, and $4.9 \mathrm{mEq} / \mathrm{L}$ measured using the CARDY meter were $4.3,3.2$, and $1.7 \%$, respectively. Mean within-day CV for plasma samples with $\left[\mathrm{K}^{+}\right]$values of $2.0,3.1$, and $4.1 \mathrm{mEq} / \mathrm{L}$ measured using the CARDY meter were $2.8,3.8$, and $4.9 \%$, respectively. The mean within-day CV for urine samples with $\left[\mathrm{K}^{+}\right]$values of 16,182 , and $310 \mathrm{mEq} / \mathrm{L}$ measured using the LAQUAtwin meter were $3.9,3.0$, and $3.4 \%$, 
respectively. The mean within-day $\mathrm{CV}$ for milk samples with $\left[\mathrm{K}^{+}\right]$values of 35,46 , and $52 \mathrm{mEq} / \mathrm{L}$ measured using the LAQUAtwin meter were 3.4, 3.2, and 4.3\%, respectively. The mean within-day $\mathrm{CV}$ for abomasal fluid samples with $\left[\mathrm{K}^{+}\right]$values of 4,22 , and $50 \mathrm{mEq} / \mathrm{L}$ measured using the LAQUAtwin meter were 5.1, 1.8, and $4.0 \%$, respectively.

The mean between-day CV determined from $20 \mathrm{~d}$ for linearity standards with $\left[\mathrm{K}^{+}\right]$values of $1.9,3.7$, and 7.5 $\mathrm{mEq} / \mathrm{L}$ measured using the CARDY meter were 4.5 , 4.1 , and $3.6 \%$, respectively.

\section{Comparison Between Whole Blood and Plasma $\left[\mathrm{K}^{+}\right]$}

Deming regression of the comparison between measured $\left[\mathrm{K}^{+}\right]$using the CARDY meter in 369 whole blood and plasma samples from 106 periparturient HolsteinFriesian cattle showed a linear relationship that was similar to the line of identity, with a slope of $0.97(95 \%$ CI: 0.91 to 1.04$)$ and an intercept of $0.19 \mathrm{mEq} / \mathrm{L}(95 \%$ CI: -0.06 to 0.44 ; Figure 1A). Between 1 and 7 whole blood samples were obtained from each cow, with a median of 3 samples per cow.

The Bland-Altman plot indicated a mean positive bias of $2.1 \%(P<0.0001$ compared with $0 \%)$ and $95 \%$ limits of agreement from -6.0 to $10.2 \%$ (Figure 1B).

\section{Method Comparison Study for Plasma $\left[K^{+}\right]$}

Deming regression for plasma $\left[\mathrm{K}^{+}\right]$measured by the CARDY meter against plasma $\left[\mathrm{K}^{+}\right]$measured by the reference method for 138 plasma samples from $27 \mathrm{Hol}-$ stein-Friesian cows indicated a proportional bias (1.07; 95\% CI: 0.99-1.15) that was not different from 1, and a constant bias $(-0.42 \mathrm{mEq} / \mathrm{L} ; 95 \%$ CI: -0.66 to -0.18$)$ that was lower than 0 (Figure 2A). Between 1 and 13 plasma samples were obtained from each cow, with a median of 4 samples per cow.

The Bland-Altman plot indicated that the ISE meter run in direct mode read $7.3 \%$ lower than the reference method $(P<0.0001$ compared with 0 , Figure $2 \mathrm{~B})$. The mean bias of $-7.3 \%$ (95\% limits of agreement from -24 to $9.4 \%$ ) approximated the recommended adjustment of $+7.5 \%$ to the indirect ISE reference method value identified in the Introduction to account for the effect of sample dilution, assuming a normal plasma protein concentration of $70 \mathrm{~g} / \mathrm{L}$.

\section{Method Comparison Studies for Urine $\left[K^{+}\right]$}

Deming regression for urine $\left[\mathrm{K}^{+}\right]$measured by the LAQUAtwin ISE meter used in an indirect mode after sample dilution against urine $\left[\mathrm{K}^{+}\right]$measured by the indirect ISE reference method for 204 urine samples from 16 Holstein-Friesian cows indicated a proportional bias $(0.99 \mathrm{mEq} / \mathrm{L} ; 95 \%$ CI: 0.95 to 1.04$)$ that was not different from 1 , and a constant bias $(-0.8 \mathrm{mEq} / \mathrm{L}$; 95\% CI: -5.3 to 3.7$)$ that was not different from 0 (Figure 3A). Between 11 and 13 urine samples were obtained from each cow, with a median of 13 samples per cow. The Bland-Altman plot indicated agreement between the 2 methods with a mean bias of $-1.4 \%$ (95\% limits of agreement from -26 to $23.2 \%$ ) that was not significantly different from $0(P=0.070$, Figure $3 \mathrm{~B})$. The percent difference was higher at low urine concentrations because of the resolution of the meter relative to the $\left[\mathrm{K}^{+}\right]$when urine $\left[\mathrm{K}^{+}\right]<50 \mathrm{mEq} / \mathrm{L}$.

Deming regression for urine $\left[\mathrm{K}^{+}\right]$measured by the LAQUAtwin ISE meter used in an indirect mode after sample dilution against urine $\left[\mathrm{K}^{+}\right]$measured by ICPOES for 203 urine samples from 16 lactating HolsteinFriesian cows indicated a proportional bias $(0.99 ; 95 \%$ CI: 0.92 to 1.05$)$ that was not different from 1 , and a constant bias $(-24 \mathrm{mEq} / \mathrm{L} ; 95 \%$ CI: -33 to -15$)$ that was different from 0 (Figure 4A). Eleven to 13 urine samples were obtained from each cow, with a median of 13 samples per cow. The Bland-Altman plot indicated poor agreement between the 2 methods with a mean bias of $-21.7 \%$ (95\% limits of agreement from -66.2 to $22.8 \%$, Figure $4 \mathrm{~B})$. The median value for urine $\left[\mathrm{K}^{+}\right]$ measured by the ISE meter was $83.0 \%$ (range, 14.6 to $113.1 \%$ ) of the value measured by ICP-OES.

\section{Method Comparison Study for Milk [K $\left.{ }^{+}\right]$}

Deming regression for milk $\left[\mathrm{K}^{+}\right]$measured by the direct LAQUAtwin ISE meter against milk $\left[\mathrm{K}^{+}\right]$measured by the indirect ISE reference method for 92 milk samples from 16 lactating Holstein-Friesian cows indicated a proportional bias $(0.89 \mathrm{mEq} / \mathrm{L}$; $95 \%$ CI: $0.82-0.96)$ that was less than 1 , and a constant bias $(3.3 \mathrm{mEq} / \mathrm{L}$; 95\% CI: 0.4-6.3) that was different from 0 (Figure 5A). Between 2 and 6 milk samples were obtained from each cow, with a median of 6 samples per cow.

The Bland-Altman plot indicated that the LAQUAtwin ISE meter run in direct mode measured fat-free milk as $3.6 \%$ (95\% limits of agreement from -11.0 to $3.9 \%)$ lower than the indirect ISE reference method ( $P$ $<0.0001$ compared with 0, Figure 5B). Similar to the effect of changes in the plasma protein concentration ([PP]) of whole blood, the extensive sample dilution in indirect potentiometry means that changes in the volume of the nonaqueous portion of the milk sample (due to the presence of milk protein) results in $\left[\mathrm{K}^{+}\right]$being underestimated. As a consequence, milk $\left[\mathrm{K}^{+}\right]$values measured by indirect ISE should be increased by $3.5 \%$ $=1 /(1-0.034)$; this estimate approximated the magnitude of the deficit in observed mean bias of $-3.6 \%$. 

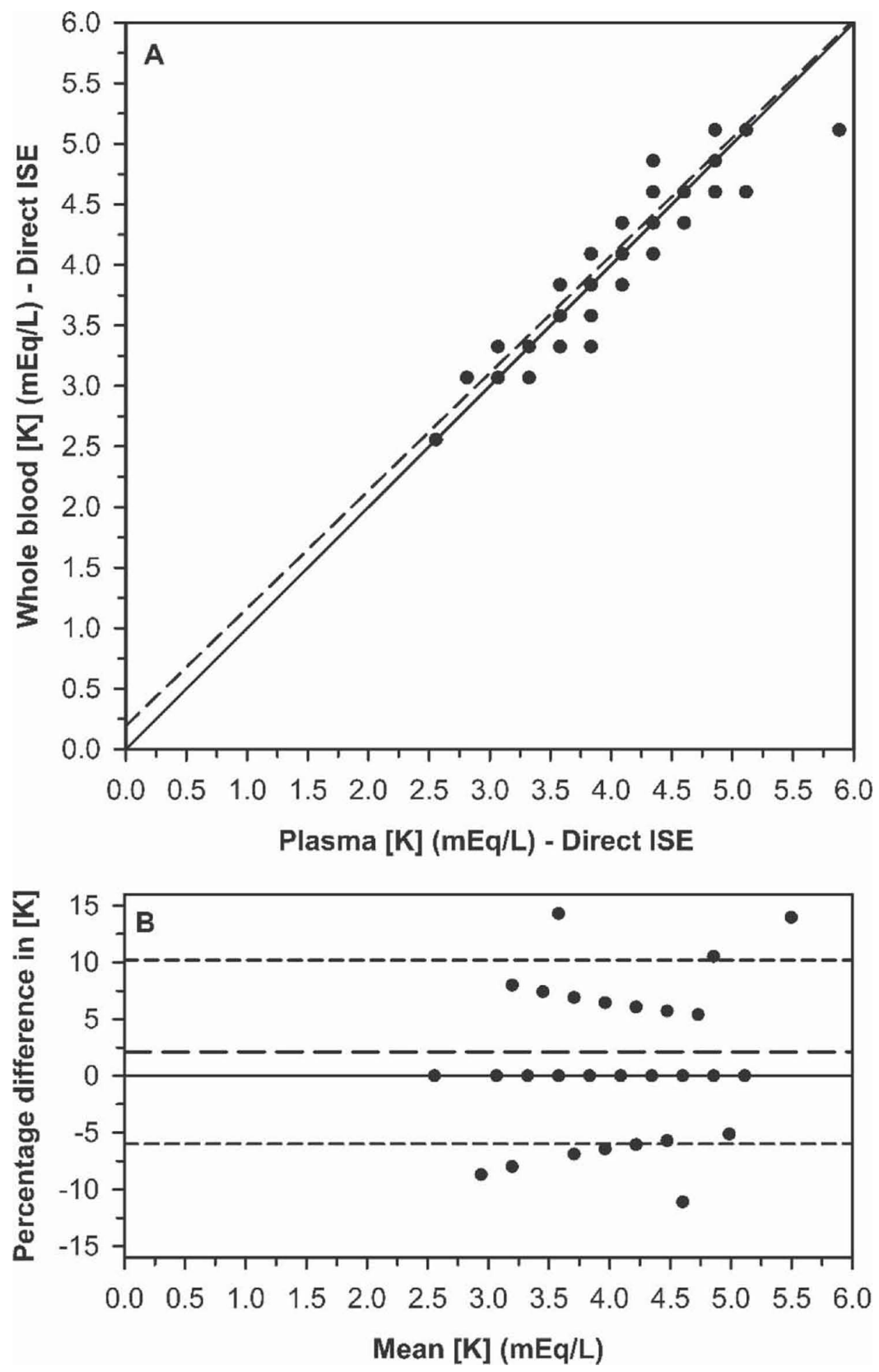

Figure 1. (A) Scatterplot of the relationship between whole blood and plasma potassium concentration ([K $\left.{ }^{+}\right]$) for 369 samples from 106 periparturient Holstein-Friesian dairy cattle. Whole blood and plasma $\left[\mathrm{K}^{+}\right]$were measured using a direct ion-selective electrode (direct ISE) method (CARDY C-131 K+ meter; Horiba Ltd., Albany, NY). Many data points are superimposed because the meter has a resolution of 0.26 $\mathrm{mEq} / \mathrm{L}$ when $\left[\mathrm{K}^{+}\right]>2.6 \mathrm{mEq} / \mathrm{L}$. The solid diagonal line is the line of identity, and the dashed line is the line of best fit from Deming regression. (B) Bland-Altman plot of the difference between whole blood and plasma $\left[\mathrm{K}^{+}\right]$measured by the meter (expressed as a percentage of their mean value) against the mean value for $\left[\mathrm{K}^{+}\right]$. The horizontal long dashed line is the mean bias and the horizontal short dashed lines reflect the $95 \%$ limits of agreement, which is equivalent to the range of differences containing $95 \%$ of future measurements. The plot indicates that the meter measures whole blood $\left[\mathrm{K}^{+}\right]$as being $2.1 \%$ higher than plasma $\left[\mathrm{K}^{+}\right]$. 

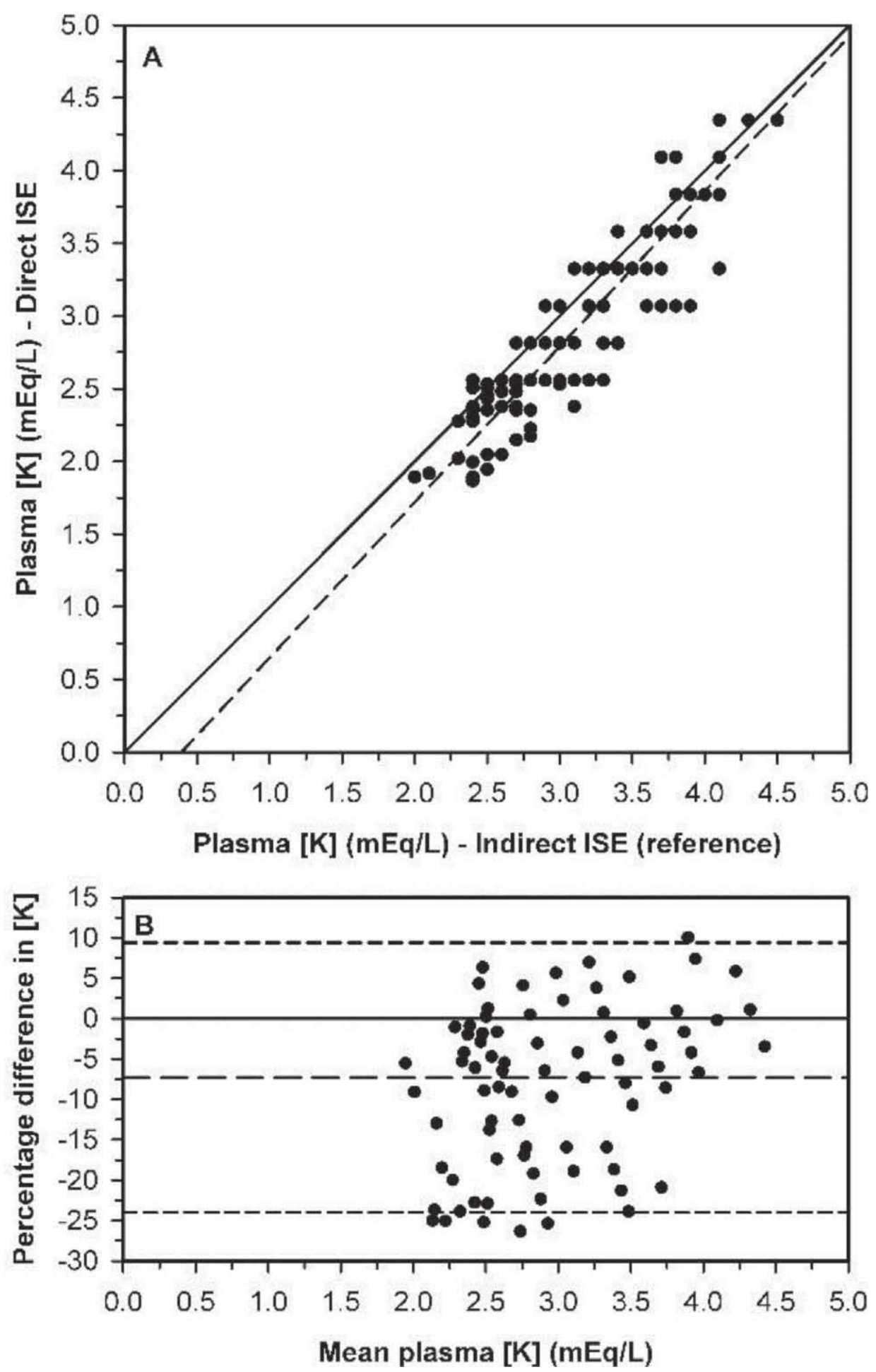

Figure 2. (A) Scatterplot of the relationship between the plasma potassium concentration $\left(\left[\mathrm{K}^{+}\right]\right)$measured by a direct ion-selective electrode (direct ISE) method (CARDY C-131 K ${ }^{+}$meter; Horiba Ltd., Albany, NY) versus the plasma $\left[\mathrm{K}^{+}\right]$measured by the reference method (indirect ISE) for 138 plasma samples. The samples were obtained from 12 healthy periparturient Holstein-Friesian cows and 15 lactating Holstein-Friesian cows with experimentally induced electrolyte and acid-base imbalances. Many data points are superimposed because the meter has a resolution of $0.26 \mathrm{mEq} / \mathrm{L}$ when $\left[\mathrm{K}^{+}\right]>2.6 \mathrm{mEq} / \mathrm{L}$. The solid diagonal line is the line of identity, and the dashed line is the line of best fit from Deming regression. (B) Bland-Altman plot of the difference between plasma $\left[\mathrm{K}^{+}\right]$measured by the meter and reference method (expressed as a percentage of their mean value) against the mean value for plasma $\left[\mathrm{K}^{+}\right]$. The horizontal long dashed line is the mean bias and the horizontal short dashed lines reflect the $95 \%$ limits of agreement, which is equivalent to the range of differences containing $95 \%$ of future measurements. The plot indicates that the meter results are $7.3 \%$ lower than those of the reference method. 

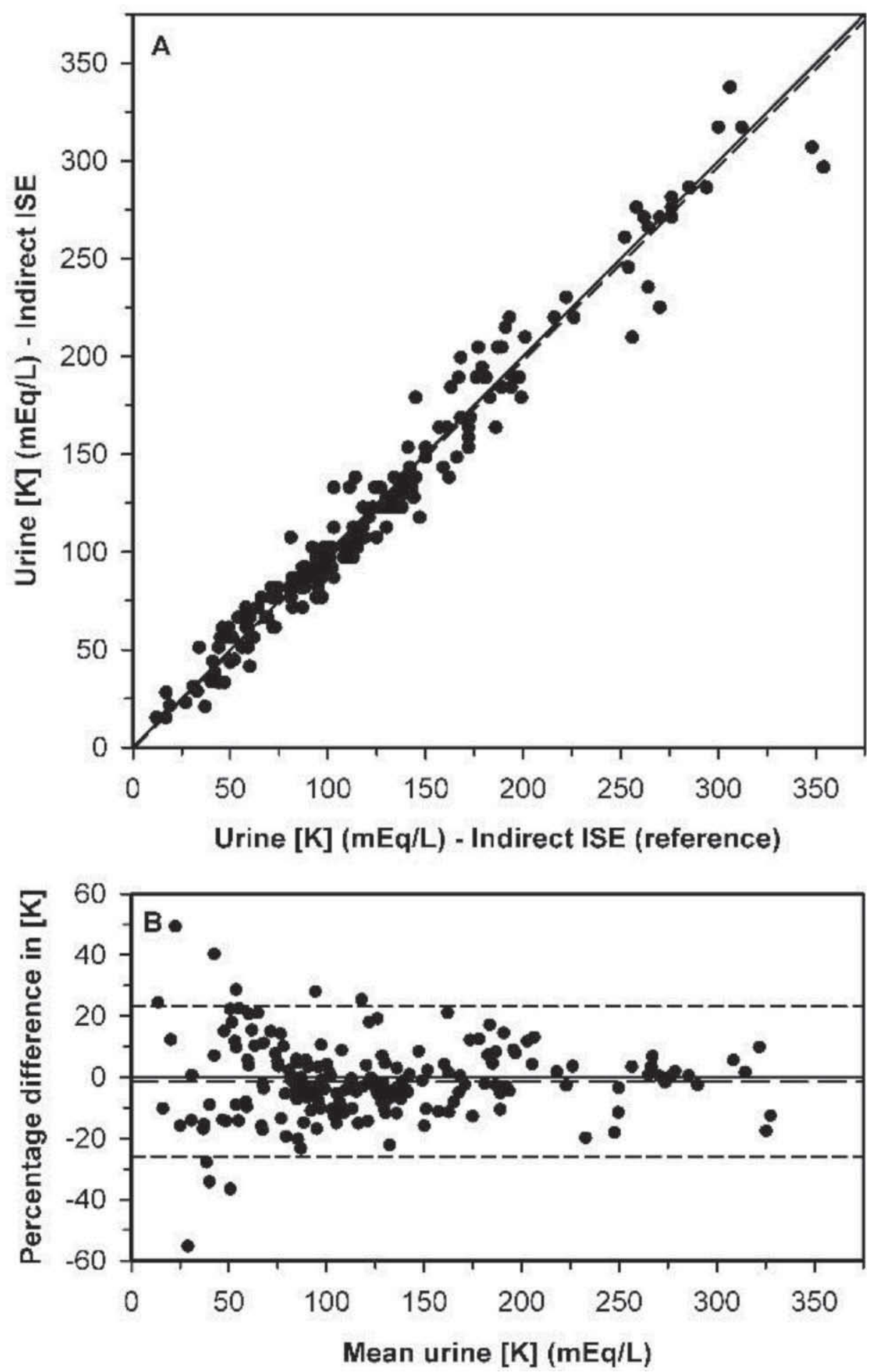

Figure 3. (A) Scatterplot indicating the relationship between the urine potassium concentration $\left(\left[\mathrm{K}^{+}\right]\right)$measured by an ion-selective electrode (indirect ISE) meter (LAQUAtwin $\mathrm{K}^{+}$meter; Horiba Ltd., Albany, NY) run in an indirect mode (1:19 dilution in distilled water) versus the urine $\left[\mathrm{K}^{+}\right]$measured by an indirect ISE reference method (1:31 dilution in distilled water). Urine samples $(\mathrm{n}=204)$ were obtained from 16 lactating Holstein-Friesian cows with experimentally induced electrolyte and acid-base imbalances. The solid diagonal line is the line of identity, and the dashed line is the line of best fit from Deming regression. (B) Bland-Altman plot of the difference between urine $\left[\mathrm{K}^{+}\right]$measured by the meter and reference method (expressed as a percentage of their mean value) against the mean value for urine $\left[\mathrm{K}^{+}\right]$. The horizontal long dashed line is the mean bias and the horizontal short dashed lines reflect the $95 \%$ limits of agreement, which is equivalent to the range of differences containing $95 \%$ of future measurements. The plot indicates that the ISE meter run in an indirect method provides equivalent results to the indirect ISE reference method. 

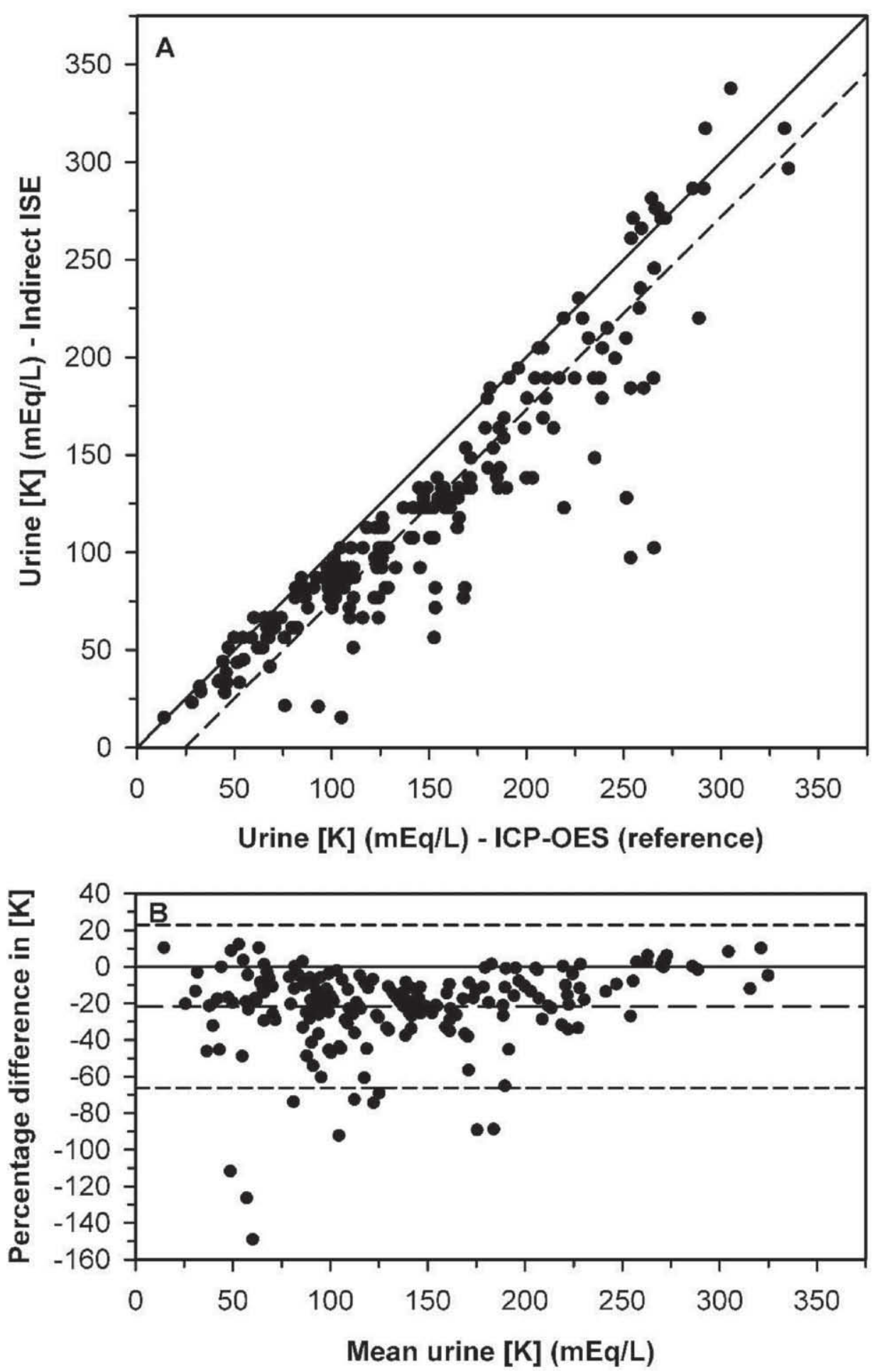

Figure 4. (A) Scatterplot indicating the relationship between the urine potassium concentration ([K $\left.{ }^{+}\right]$) measured by an ion-selective electrode (indirect ISE) meter (LAQUAtwin $\mathrm{K}^{+}$meter; Horiba Ltd., Albany, NY) run in an indirect mode (1:19 dilution in distilled water) versus the urine $\left[\mathrm{K}^{+}\right]$measured by an inductively coupled plasma-optical emission spectroscopy (ICP-OES) reference method. Urine samples $(\mathrm{n}=203)$ were obtained from 16 lactating Holstein-Friesian cows with experimentally induced electrolyte and acid-base imbalances. The solid diagonal line is the line of identity, and the dashed line is the line of best fit from Deming regression. (B) Bland-Altman plot of the difference between urine $\left[\mathrm{K}^{+}\right]$measured by the ISE meter and reference method (expressed as a percentage of their mean value) against the mean value for urine $\left[\mathrm{K}^{+}\right]$. The horizontal long dashed line is the mean bias and the horizontal short dashed lines reflect the $95 \%$ limits of agreement, which is equivalent to the range of differences containing $95 \%$ of future measurements. The plot indicates that the ISE meter is not equivalent to the ICP-OES reference method. 

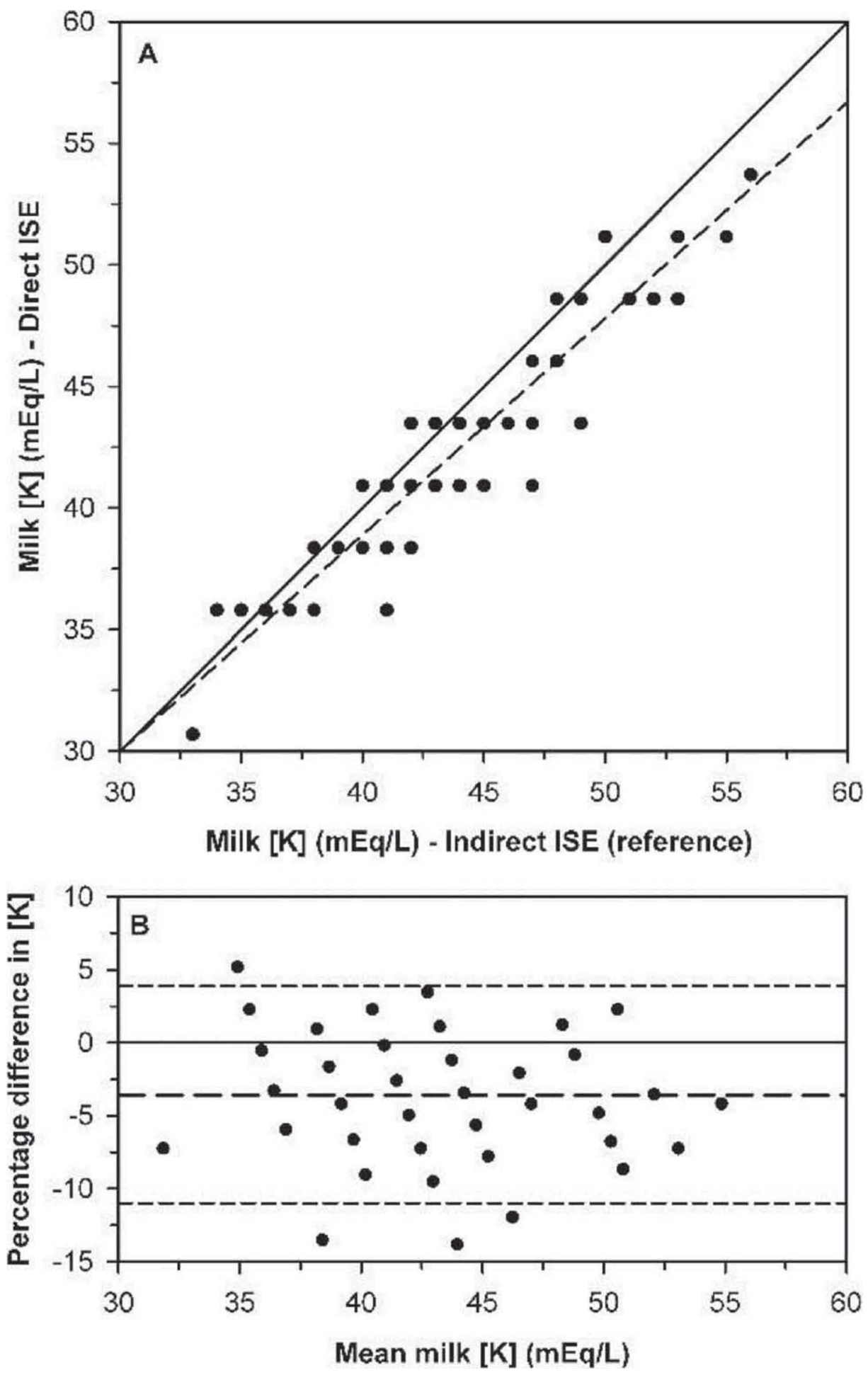

Figure 5. (A) Scatterplot indicating the relationship between the milk potassium concentration $\left(\left[\mathrm{K}^{+}\right]\right)$measured by a direct ion-selective electrode (direct ISE) method (LAQUAtwin $\mathrm{K}^{+}$meter; Horiba Ltd., Albany, NY) versus the milk $\left[\mathrm{K}^{+}\right]$measured by an indirect ISE reference method (1:31 dilution in distilled water). Ninety-two milk samples were obtained from 16 lactating Holstein-Friesian cows with experimentally induced electrolyte and acid-base imbalances. Many data points are superimposed because the meter has a resolution of $2.6 \mathrm{mEq} / \mathrm{L}$ when $\left[\mathrm{K}^{+}\right]$ $>26 \mathrm{mEq} / \mathrm{L}$. The solid diagonal line is the line of identity, and the dashed line is the line of best fit from Deming regression. (B) Bland-Altman plot of the difference between milk $\left[\mathrm{K}^{+}\right]$measured by the direct ISE method and indirect ISE reference method (expressed as a percentage of their mean value) against the mean value for milk $\left[\mathrm{K}^{+}\right]$. The horizontal long dashed line is the mean bias and the horizontal short dashed lines reflect the $95 \%$ limits of agreement, which is equivalent to the range of differences containing $95 \%$ of future measurements. The plot indicates that the meter results are $3.6 \%$ lower than those of the reference method. 


\section{Method Comparison Study for Abomasal Fluid $\left[\mathrm{K}^{+}\right]$}

Deming regression for abomasal fluid $\left[\mathrm{K}^{+}\right]$measured by the LAQUAtwin meter against abomasal fluid $\left[\mathrm{K}^{+}\right]$ measured by the ISE reference method for 94 samples from 6 healthy Holstein-Friesian bull calves indicated a proportional bias $(0.99 \mathrm{mEq} / \mathrm{L} ; 95 \%$ CI: 0.95 to 1.04$)$ that was not different from 1 , and a constant bias $(0.9$ $\mathrm{mEq} / \mathrm{L} ; 95 \%$ CI: -0.6 to 2.4$)$ that was not different from 0 (Figure 6A). Between 2 and 6 milk samples were obtained from each calf, with a median of 6 samples per calf.

The Bland-Altman plot indicated agreement between the 2 methods with a mean bias of $1.9 \%$ (95\% limits of agreement from -17.0 to $20.8 \%$ ) that was greater than $0(P=0.018$, Figure 6B).

\section{DISCUSSION}

To our knowledge, this is the first study to investigate the analytical performance of the handheld Horiba ISE meters for measuring the $\left[\mathrm{K}^{+}\right]$in different biological fluids from cattle or other domestic animals. We found that the ISE meter run in direct mode measured plasma $\left[\mathrm{K}^{+}\right]$as being $7.3 \%$ lower than the indirect ISE reference method, consistent with the recommended adjustment of $+7.5 \%$, assuming a normal $[\mathrm{PP}]$ of 70 g/L (Maas et al., 1985; Burnett et al., 2000; D'Orazio et al., 2000). The ISE meter run in direct mode measured fat-free milk $\left[\mathrm{K}^{+}\right]$as being $3.6 \%$ lower than the indirect ISE reference method, consistent with the recommended adjustment of $+3.5 \%$, assuming a herd milk protein percentage of $3.4 \%$. The ISE meter accurately measured abomasal fluid $\left[\mathrm{K}^{+}\right]$, but underestimated the true value for urine $\left[\mathrm{K}^{+}\right]$in several samples.

We determined that the $\left[\mathrm{K}^{+}\right]$measured in whole blood was $2.1 \%$ higher than that measured in plasma after centrifugation of the whole blood sample. This finding was similar to that previously reported, whereby whole blood $\left[\mathrm{K}^{+}\right]$was measured as being $2.0 \%$ (valinomycinpolyvinyl chloride membrane ISE) or $4.0 \%$ (polyvinyl chloride membrane ISE) higher than the corresponding plasma sample. The cause for this difference is unknown, but it does not appear to be hemolysis during sample handling (Fogh-Andersen et al., 1984). Consideration of the mean bias relative to reference methods suggests that when the Horiba ISE meter is used directly in whole blood or plasma, the measured $\left[\mathrm{K}^{+}\right]$value should be increased by $5.2 \%$ ( $7.3 \%$ minus $2.1 \%$ ) for whole blood and $7.3 \%$ for plasma. Similarly, when the Horiba ISE meter is used directly in milk from dairy herds with typical bulk tank milk fat and protein concentrations, the measured $\left[\mathrm{K}^{+}\right]$value should be increased by $7.3 \%$ in whole milk or by the bulk tank milk protein concentration in milk samples that have been centrifuged and the fat layer discarded, as in the study reported here. No adjustment in the measured value is needed when abomasal fluid is analyzed using the Horiba ISE meter in direct mode.

The results of the study reported here support the presence of an interfering anion in bovine urine; our findings are similar to those in a 1988 report related to sheep urine (Brooks et al., 1988). The interfering agent does not appear to be specifically related to a herbivore diet because it has been identified in cats (Brooks et al., 1988) and does not appear to be present in llama urine (Christopher et al., 1996).

Although the meter provides a total display range for $\left[\mathrm{K}^{+}\right]$of 0 to $257 \mathrm{mEq} / \mathrm{L}$, a limitation of the meter is that the measurement resolution changes across 3 ranges, being $0.026 \mathrm{mEq} / \mathrm{L}$ up to $2.6 \mathrm{mEq} / \mathrm{L}, 0.26 \mathrm{mEq} / \mathrm{L}$ from 2.6 to $25.7 \mathrm{mEq} / \mathrm{L}$, and $2.6 \mathrm{mEq} / \mathrm{L}$ from 26 to $257 \mathrm{mEq} / \mathrm{L}$. The within-day CV values in whole blood, plasma, and urine ranged from 1.7 to $5.1 \%$, reflecting the resolution for each of the 3 ranges. The measurement resolution is adequate for clinical use, but may be a limitation in some research studies. Improved resolution, particularly over the range of 2.6 to $4.0 \mathrm{mEq} / \mathrm{L}$, would likely improve the clinical utility of the meter for monitoring changes in whole-blood $\left[\mathrm{K}^{+}\right]$in cattle being treated for hypokalemia.

This study had 2 additional limitations. First, we did not explore the analytical performance of the meter in cattle with hyperkalemia, which is rare in adult cattle but common in neonatal calves with diarrhea (Constable et al., 2013; Trefz et al., 2013, 2015). We believe it is more appropriate to complete a separate study to fully evaluate the analytical performance of the meter in calves with hyperkalemia because diarrheic neonatal calves have a much lower $[\mathrm{PP}]$ than sick adult cattle, as well as higher plasma phosphorous concentrations and lower blood pH (Trefz et al., 2013, 2015), all of which may affect analytical performance. Second, the study used multiple samples from each animal and ignored the potential effect of clustering during analysis. The authors are not aware of a statistical method that simultaneously adjusts the estimated values for the slope and intercept from Deming regression for the effect of clustering. Bland-Altman plots can be adjusted for multiple observations per individual (Bland and Altman, 2003, 2007), but such adjustment has no effect on the estimate for bias and minimal effect on decreasing the $95 \%$ confidence interval whenever the number of measurements per subject is small and less than the number of subjects (Bland and Altman, 2007), as in the study reported here.

In conclusion, the Horiba handheld ISE meters are practical, rapid, and accurate point-of-care instruments 

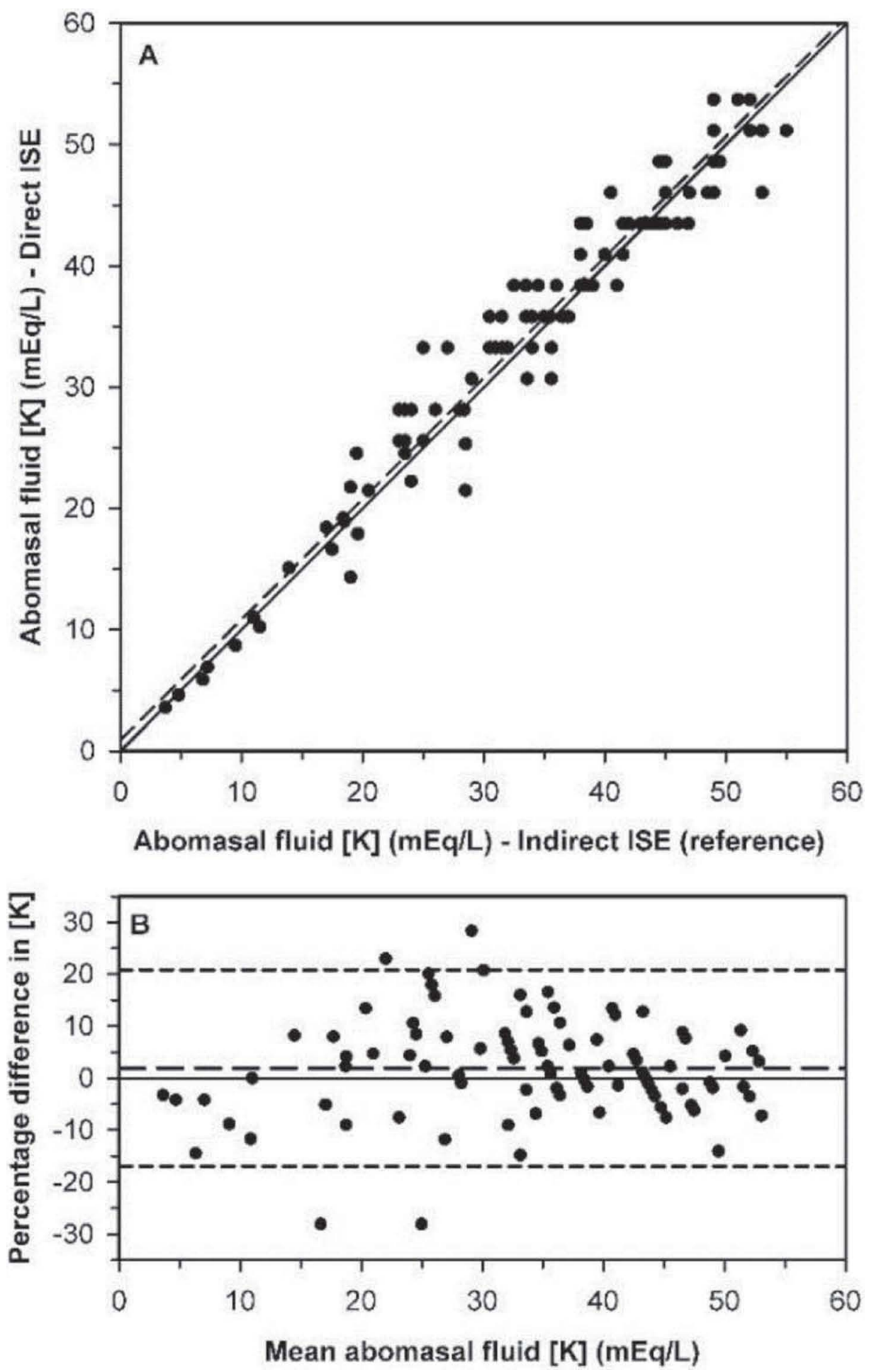

Figure 6. (A) Scatterplot indicating the relationship between the abomasal fluid potassium concentration $\left(\left[\mathrm{K}^{+}\right]\right)$measured by a direct ionselective electrode (direct ISE) method (LAQUAtwin $\mathrm{K}^{+}$meter; Horiba Ltd., Albany, NY) versus the abomasal fluid [ $\left.\mathrm{K}^{+}\right]$measured by an indirect ISE reference method (1:31 dilution in distilled water). Ninety-four samples were obtained periodically from 6 Holstein-Friesian bull calves with an abomasal cannula after they suckled fresh cow's milk that clotted in their abomasum. Some points are superimposed because the meter has a resolution of $2.6 \mathrm{mEq} / \mathrm{L}$ when $\left[\mathrm{K}^{+}\right]>26 \mathrm{mEq} / \mathrm{L}$. The solid diagonal line is the line of identity, and the dashed line is the line of best fit from Deming regression. (B) Bland-Altman plot of the difference between abomasal fluid $\left[\mathrm{K}^{+}\right]$measured by the direct ISE method and indirect ISE reference method (expressed as a percentage of their mean value) against the mean value for abomasal fluid $\left[\mathrm{K}^{+}\right]$. The horizontal long dashed line is the mean bias and the horizontal short dashed lines reflect the $95 \%$ limits of agreement, which is equivalent to the range of differences containing $95 \%$ of future measurements. The plot indicates that the direct ISE method is equivalent to the indirect ISE reference method. 
suitable for measuring $\left[\mathrm{K}^{+}\right]$in whole blood, plasma, milk, and abomasal fluid samples from dairy cattle. The meter cost is relatively low and once purchased, the low cost of calibration solutions results in an extremely low cost per test ( $\$ 0.02$ to $\$ 0.03 /$ test). The Horiba handheld ISE meters can be used to measure ionized $\left[\mathrm{K}^{+}\right]$in bovine urine, but they are not suitable for measuring total $\left[\mathrm{K}^{+}\right]$in bovine urine. Although it was not investigated in the study reported here, this result might be due to the presence of unidentified anions in bovine urine that bind potassium ions and thereby interfere with the measurement of $\left[\mathrm{K}^{+}\right]$.

\section{ACKNOWLEDGMENTS}

The authors thank all the staff at the Purdue Dairy Research and Education Center, and the staff at the Clinical Pathology Laboratory, College of Veterinary Medicine, at the University of Illinois at UrbanaChampaign.

\section{REFERENCES}

Anker, P., H. B. Jenny, U. Wuthier, R. Asper, D. Ammann, and W. Simon. 1983. Determination of K in blood serum with a valinomycin based silicone rubber membrane of universal applicability to body fluids. Clin. Chem. 29:1447-1448.

Bland, J. M., and D. G. Altman. 2003. Applying the right statistics: analysis of measurement studies. Ultrasound Obstet. Gynecol. $22: 85-93$.

Bland, J. M., and D. G. Altman. 2007. Agreement between methods of measurement with multiple observations per individual. J. Biopharm. Stat. 17:571-582.

Brooks, C. L., F. Garry, and M. S. Swartout. 1988. Effect of an interfering substance on determination of potassium by ion-specific potentiometry in animal urine. Am. J. Vet. Res. 49:710-714.

Burnell, J. M., and B. H. Scribner. 1957. Serum potassium concentration as a guide to potassium need. J. Am. Med. Assoc. 164:959962.

Burnett, R. W., A. K. Covington, N. Fogh-Andersen, W. R. Külpmann, A. Lewenstam, A. H. Maas, O. Müller-Plathe, C. Sachs, O. Siggaard-Andersen, A. L. VanKessel, and W. G. Zijlstra. 2000. Recommendations for measurement of and conventions for reporting sodium and potassium by ion-selective electrodes in undiluted serum, plasma or whole blood. Clin. Chem. Lab. Med. 38:10651071.

Buzanovskii, V. A. 2015. Chronology of the research on methods for determining the potassium concentration in human blood. Rev. J. Chem. 5:1-20.

Christopher, M. M., E. B. Belknap, D. J. Meyer, M. N. Lackey, and L. M. Vap. 1996. Comparison of methods for sodium and potassium determination in llama urine. Am. J. Vet. Res. 57:25-30.

Constable, P. D., W. Grunberg, and L. Carstensen. 2009. Comparative effects of two oral rehydration solutions on milk clotting, abomasal luminal $\mathrm{pH}$, and abomasal emptying rate in suckling calves. J. Dairy Sci. 92:296-312.

Constable, P. D., W. Grünberg, R. Staufenbiel, and H. R. Stampfli. 2013. Clinicopathological associations with hypokalemia in lactating dairy cows with abomasal displacement or abomasal volvulus. J. Am. Vet. Med. Assoc. 242:826-835.

Constable, P. D., M. W. H. Hiew, S. Tinkler, and J. Townsend. 2014 Efficacy of oral potassium chloride administration in treating lactating dairy cows with experimentally induced hypokalemia, hypochloremia, and alkalemia. J. Dairy Sci. 97:1413-1426.
Constable, P. D., G. St. Jean, B. L. Hull, D. M. Rings, and G. F. Hoffsis. 1991. Preoperative prognostic indicators in cattle with abomasal volvulus. J. Am. Vet. Med. Assoc. 198:2077-2085.

D'Orazio, P., W. G. Miller, G. L. Myers, D. T. Basil, J. H. Eckfeldt, S. A. Evans, G. A. Graham, P. J. Parsons, and N. V. Stanton. 2000. Standardization of sodium and potassium ion-selective electrode systems to the flame photometric reference method; Approved Standard-Second Edition, C29-A2 [electronic document]. CLSI, Wayne, PA.

Dimeski, G., and R. J. Barnett. 2005. Effects of total plasma protein concentration on plasma sodium, potassium and chloride measurements by an indirect ion selective electrode measuring system. Crit. Care Resusc. 7:12-15.

Dimeski, G., P. Mollee, and A. Carter. 2006. Effects of hyperlipidemia on plasma sodium, potassium, and chloride measurements by indirect ion selective electrode measuring system. Clin. Chem. $52: 155-156$.

Dimeski, G., T. J. Morgan, J. J. Presneill, and B. Venkatesh. 2012. Disagreement between ion selective electrode direct and indirect sodium measurements: estimation of the problem in a tertiary referral hospital. J. Crit. Care 27:326.e9-326.e16.

Fogh-Andersen, N., P. D. Wimberley, J. Thode, and O. Siggaard-Andersen. 1984. Determination of sodium and potassium with ionselective electrodes. Clin. Chem. 30:433-436.

Grünberg, W., S. S. Donkin, and P. D. Constable. 2011. Periparturient effects of feeding a low dietary cation-anion difference diet on acidbase, calcium, and phosphorus homeostasis and on intravenous glucose tolerance test in high-producing dairy cows. J. Dairy Sci. 94:727-745.

Hartland, A. J., and R. H. Neary. 1999. Serum potassium is unreliable as an estimate of in vivo plasma potassium. Clin. Chem. 45:1091-1092

Hashem, M. A., and H. A. Amer. 2008. Hormonal and biochemical anomalies in dairy cows affected by retained fetal membranes. Vet. On-Line Int. J. Vet. Med. Accessed Apr. 26, 2016. http://priory. com/vet/cow_fetal_membrane.htm.

Hitti, I. K. A., and J. D. R. Thomas. 1985. Ion-selective electrode determination of calcium and potassium in bovine skim-milk powder. Anal. Lett. 18:975-983.

Holt, C., D. G. Dalgleish, and R. Jenness. 1981. Calculation of the ion equilibria in milk diffusate and comparison with experiment. Anal. Biochem. 113:154-163.

Jain, A., I. Subhan, and M. Joshi. 2009. Comparison of the point-ofcare blood gas analyzer versus the laboratory auto-analyzer for the measurement of electrolytes. Int. J. Emerg. Med. 2:117-120.

Jenny, H. B., C. Riess, D. Ammann, B. Magyar, R. Asper, and W. Simon. 1980. Determination of $\mathrm{K}^{+}$in diluted and undiluted urine with ion-selective electrodes. Mikrochim. Acta 74:309-315.

Kalaitzakis, E., N. Panousis, N. Roubies, E. Kaldrymidou, and H. Karatzias. 2010. Macromineral status of dairy cows with concurrent left abomasal displacement and fatty liver. N. Z. Vet. J. 58:307-311.

Kimura, K., T. Maeda, H. Tamura, and T. Shono. 1979. Potassiumselective PVC membrane electrodes based on bis and poly(crown ether)s. J. Electroanal. Chem. 95:91-101.

Krejčová, A., T. Černohorský, and E. Čurdová. 2001. Determination of sodium, potassium, magnesium and calcium in urine by inductively coupled plasma atomic emission spectrometry. The study of matrix effects. J. Anal. At. Spectrom. 16:1002-1005.

Ladenson, J. H. 1979. Evaluation of an instrument (Nova-1) for direct potentiometric analysis of sodium and potassium in blood and their indirect potentiometric determination in urine. Clin. Chem. 25:757-763.

Lang, T., P. Prinsloo, A. F. Broughton, N. Lawson, and C. B. Marenah. 2002. Effect of low protein concentration on serum sodium measurement; Pseudohypernataremia and pseudonormonatraemia. Ann. Clin. Biochem. 39:66-67.

Le Graët, Y., and G. Brulé. 1993. Effects of pH and ionic strength on distribution of mineral salts in milk. Lait 73:51-60.

Maas, A. H., O. Siggaard-Andersen, H. F. Weisberg, and W. G. Zijlstra. 1985. Ion-selective electrodes for sodium and potassium: a new 
problem of what is measured and what should be reported. Clin. Chem. 31:482-485.

Martin, R. F. 2000. General Deming regression for estimating systematic bias and its confidence interval in method-comparison studies. Clin. Chem. 46:100-104

Megahed, A. A., M. W. H. Hiew, J. R. Townsend, J. B. Messick, and P. D. Constable. 2015. Evaluation of an electrochemical point-of-care meter for measuring glucose concentration in blood from periparturient dairy cattle. J. Vet. Intern. Med. 29:1718-1727.

Mekmene, O., Y. Le Graët, and F. Gaucheron. 2010. Theoretical model for calculating ionic equilibria in milk as a function of $\mathrm{pH}$ : Comparison to experiment. J. Agric. Food Chem. 58:4440-4447.

Neff, A. W., N. D. Connor, and H. S. Bryan. 1960. Studies on $9 \alpha$-fluroprednisolone acetate, a new synthetic corticosteroid for the treatment of bovine ketosis. J. Dairy Sci. 43:553-562.

Oesch, U., D. Ammann, and W. Simon. 1986. Ion-selective membrane electrodes for clinical use. Clin. Chem. 32:1448-1459.

Ohtsuka, H., K. Mori, A. Hatsugaya, M. Koiwa, H. Sato, T. Yoshino, and K. Takahashi. 1997. Metabolic alkalosis in coliform mastitis. J. Vet. Med. Sci. 59:471-472.

Radostits, O. M., C. C. Gay, K. W. Hinchcliff, and P. D. Constable. 2007. Veterinary Medicine: A Textbook of the Diseases of Cattle, Horses, Sheep, Pigs and Goats. 10th ed. Elsevier Ltd., London, UK.
Rohn, M., B. A. Tenhagen, and W. Hofmann. 2004. Survival of dairy cows after surgery to correct abomasal displacement: 1 . Clinical and laboratory parameters and overall survival. J. Vet. Med. A Physiol. Pathol. Clin. Med. 51:294-299.

Sattler, N., and G. Fecteau. 2014. Hypokalemia syndrome in cattle. Vet. Clin. North Am. Food Anim. Pract. 30:351-357.

Smith, G. W., P. D. Constable, and D. E. Morin. 2001. Ability of hematologic and serum biochemical variables to differentiate gramnegative and gram-positive mastitis in dairy cows. J. Vet. Intern. Med. 15:394-400.

Trefz, F. M., P. D. Constable, and I. Lorenz. 2015. Quantitative physicochemical analysis of acid-base balance and clinical utility of anion gap and strong ion gap in 806 neonatal calves with diarrhea. J. Vet. Intern. Med. 29:678-687.

Trefz, F. M., P. D. Constable, C. Sauter-Louis, A. Lorch, G. KnubbenSchweizer, and I. Lorenz. 2013. Hyperkalemia in neonatal diarrheic calves depends on the degree of dehydration and the cause of the metabolic acidosis but does not require the presence of acidemia. J. Dairy Sci. 96:7234-7244.

Wittek, T., P. D. Constable, and D. E. Morin. 2005. Abomasal impaction in Holstein-Friesian cows: 80 cases (1980-2003). J. Am. Vet. Med. Assoc. 227:287-291. 